\title{
Holistic school safety education from education for sustainable development (ESD) perspective
}

\author{
Lada Rozhdestvenskaya ${ }^{1, *}$, and Vladimir Korotenko ${ }^{2,3}$ \\ ${ }^{1}$ Novosibirsk State Technical University, Prospekt K. Marksa, 20, 630073 Novosibirsk, Russia \\ ${ }^{2}$ National Academy of Science KR, Abdymomunov str., 328/105,720001 Bishkek, Kyrgyz Republic \\ ${ }^{3}$ Ecological Movement BIOM, Abdymomunov str., 328/105, 720001 Bishkek, Kyrgyz Republic
}

\begin{abstract}
Safety is the most important and essential condition for sustainability. In turn, the implementation of the principles of sustainability in the formation of the educational environment is inextricably linked with the provision of the formation of new competencies. During the study, the authors determined safety parameters, developed a method for monitoring the selected parameters, built "safety radars" for educational institutions, reflecting the current and target state, developed recommendations to achieve an optimal level of safety. Based on the results of the study, a safety standard was developed, which received the status of a regulatory legal act at the country level, which ensured its implementation into practice. The results of the study show that the use of integrated practices to ensure the safety of the educational process can become a basic scenario for the development of new educational programs in the interests of sustainable development.
\end{abstract}

\section{Introduction}

More countries are recognizing education for sustainable development as an integral part of quality education and a key factor for sustainable development itself. The reorientation of pedagogic education towards sustainability is a pervasive trend. Education for sustainable development is the contribution of the world's education, public awareness, and learning systems to the path of humanity to a more sustainable future $[1,2,3]$.

Sustainable development in simple terms is perceived as an integral resultant interaction of human health and well-being, a sustainable economy (including poverty reduction, consumption, and waste management), and a sustainable environment, ensuring high quality of life for the population. Our quality of life now and in the future will depend on our continued impact on the Earth's resources to secure the basic requirements for existence and equitable social and economic development.

Is characterized by people coexisting harmoniously within local, national, and global communities, and with nature. A sustainable society is one that is physically, psychologically, spiritually, and socially healthy. From this point of view, building on the example of a separate school of a social model that ensures the safety of the environment

\footnotetext{
*Corresponding author: 1ada2006job@mail.ru
} 
and internal interactions between participants in terms of physical, mental, informational, ecological interaction is a new pedagogical approach that makes it possible to demonstrate to all interested parties through the experience of solving local problems of ensuring their safety the relationship to sustainability and the potential for the dissemination and scaling of these practices to impact the sustainable development of a community, a country, and even the global world.

The prerequisites for the described experiment were the understanding that the world needs education for sustainable development more than ever. A new global framework on ESD is currently under preparation to build education systems that support learners of all ages to be active contributors to more peaceful and sustainable societies and develop a sense of responsibility for our planet in line with the 17 Sustainable Development Goals $[4,5,6]$. And modern education for sustainable development (ESD) requires people to acquire "key competencies" aligning with notions of transformational learning, in addition to other generic and context-specific competencies [7,8,9].

New challenges associated with the emergence of new threats, such as COVID-19, attach value to the previously accumulated experience in the safety of the educational process itself and the ability of education to adapt to a rapidly changing environment and new conditions for achieving sustainability.

Security in the broadest sense characterizes a stable way of being an object, the preservation of its identity in the face of internal and external negative influences. Ensuring security expresses the possibility and ability of an object for self-preservation and further evolutionary self-organization under negative influences, threats, and dangers. Security is always associated with the preservation of an object and development - with its change.

In the English-language literature, the closest term is "nexus": "security-development nexus" $[10,11,20]$. "Nexus" as a term expresses only the interconnection of the concepts "development" and "security", and the concept of "measure" also claims to be their optimal ratio. This measure (in a philosophical sense) determines the ability of a certain system to the maximum possible integral-progressive development with the necessary and sufficient degree of its security. The development-security nexus has become a central focus of policy, practice, and thought. Emerging literature, reports, and policies reference the mutually reinforcing tendencies between security and development [12].

Thus, preference is given to the progressive evolutionary processes of development, which ensure the security of the social or socio-natural system in a certain rather narrow corridor (called the security corridor). The most secure is a system able to preserve itself based on progressive development, which is possible only if occurs in the security corridor.

The inclusion of security problems in education at various levels so far concerns only certain aspects and individual courses and areas of education, mainly related to national, food, information, environmental, technological security, safety engineering, life safety, etc. The analyzed materials $[13,14,15,16,17,18,19]$ show that the most developed areas are training in ensuring the sustainability of food systems, teaching healthy and sustainable eating behavior, maintaining the sustainability and safety of environmental practices; issues of integrated security training (in connection with terrorist threats or threats of natural disasters) are actively being considered too.

At the same time, the combination of more than 2-3 areas and the systemic perception of the "security - sustainability" complex is rather an exception in the modern pedagogical practice of education for sustainable development (ESD). In this regard, we formulated the following logical framework for the study, based on the hypothesis that the influence of the surrounding school environment is reflected in the health indicators and the quality of the educational process of schoolchildren. Improving the quality of the parameters of the educational environment leads to an improvement in the health indicators of schoolchildren and a decrease in social costs at different levels. 
The basis of a new approach to socio-economic changes necessary for the transition to Sustainable Development lies in the formation of a new type of ecological (nature-centered) worldview. The basic mechanism for the formation of a new person and, accordingly, a new "green" development paradigm is education, namely Education for Sustainable Development. "Green" economic development seems to be a promising vector for the sustainable development of Kyrgyzstan in the long term. Strengthening the natural foundations of the environmental safety is an essential element of the survival and sustainability of both Kyrgyzstan and the planet in general. On the one hand, at the national level, the country has declared its commitment to the ideology of sustainable development. On the other hand, the creation of a unified, integrated ecological worldview is a difficult process and requires a profound restructuring of both the decision-making and education systems.

The regulatory legal framework still weakly regulates the issues of introducing ESD into programs and textbooks for all levels of education, and also does not prescribe specific mechanisms of interaction between education authorities and educational organizations. Themes of sustainable development, including climate change and other "green" themes, should be cross-cutting for the subject standards of all educational areas that are being prepared for schools, and contribute to the reorientation of the science or subject-centric approach to a competence-based approach, which is based on changes in knowledge, skills, and attitudes of students, expressed through the concept of competence - a dynamic parameter, connected, on the one hand, to age-related changes in mental status, and on the other hand, to the expectation of the state and society from the education system.

Thus, a nexus of basic concepts emerges: security as one of the conditions for a child's self-fulfillment, an educational environment (in the broadest sense of the word) that enables the child to fulfill himself and transfer to sustainable development.

To confirm or refute the hypothesis, the monitoring and analysis of key parameters of the educational environment were carried out, namely: air-thermal regime, artificial lighting, $\mathrm{CO}_{2}$ concentration in school premises, access to safe drinking water, sanitary conditions, hygiene (water, sanitation, health) in the school, and perception of security of physical school environment by students.

\section{Materials and Methods}

The monitoring involved the investigation and assessment of the sanitary and hygienic conditions as an ecological factor of the school environment that affects the health of students:

- assessment of the perception of the level of comfort by students;

- assessment of indicators of the state of key parameters of the microclimate of school premises: air-thermal regime, artificial illumination, $\mathrm{CO}_{2}$ concentration;

- the compliance of the actual parameters of the microclimate in the premises of school classrooms with sanitary and hygienic standards that ensure a safe learning environment for students.

The monitoring of the security of the physical school environment applied empirical research methods, such as survey, observation, review of documents. In this study, a faceto-face group questionnaire survey was conducted, assuming that the interviewee fills out the questionnaire himself in the presence of the interviewer. The survey was to assess the sensitivity of children's perception of comfort: air temperature, ventilation, air freshness, lighting in school classes. All questions in the questionnaire are related to the attitude of students to key factors in the physical environment that can adversely affect the body. To assess the parameters of the microclimate and artificial illumination, instrumental measurements were used. 
The parameters (indicators) that meet the goals of the security of the physical school environment and the factors influencing the achievement of this goal were appraised by points.

Indicator assessment system, points:

0 - inactive/bad/absent/no;

1 - developing/initial level/limited;

2 - developed/formed/good/yes.

Checklists were developed for data analysis. Key school-level indicators assessed the degree of compliance of each indicator with regulatory requirements.

To visually see and evaluate different aspects of the environment, a graphical model for assessing the safety of the school environment was used - a radar diagram, the coordinate axes of which are the values of the key indicators of the subject of monitoring - the safety radar (Fig. 1). The overall value of the safety level is defined as the ratio of the actual surface area of the corresponding radar chart to the surface area of a radar chart plotted at the standard values of the criteria. Key indicators of the security of the school environment were taken as the chart axes.

The result of the study was to create a new environment that itself would become a serious learning (educational) factor, including due to new equipment and the availability of various zones that allow children to use them both in the learning process and for physical and psychological relief.

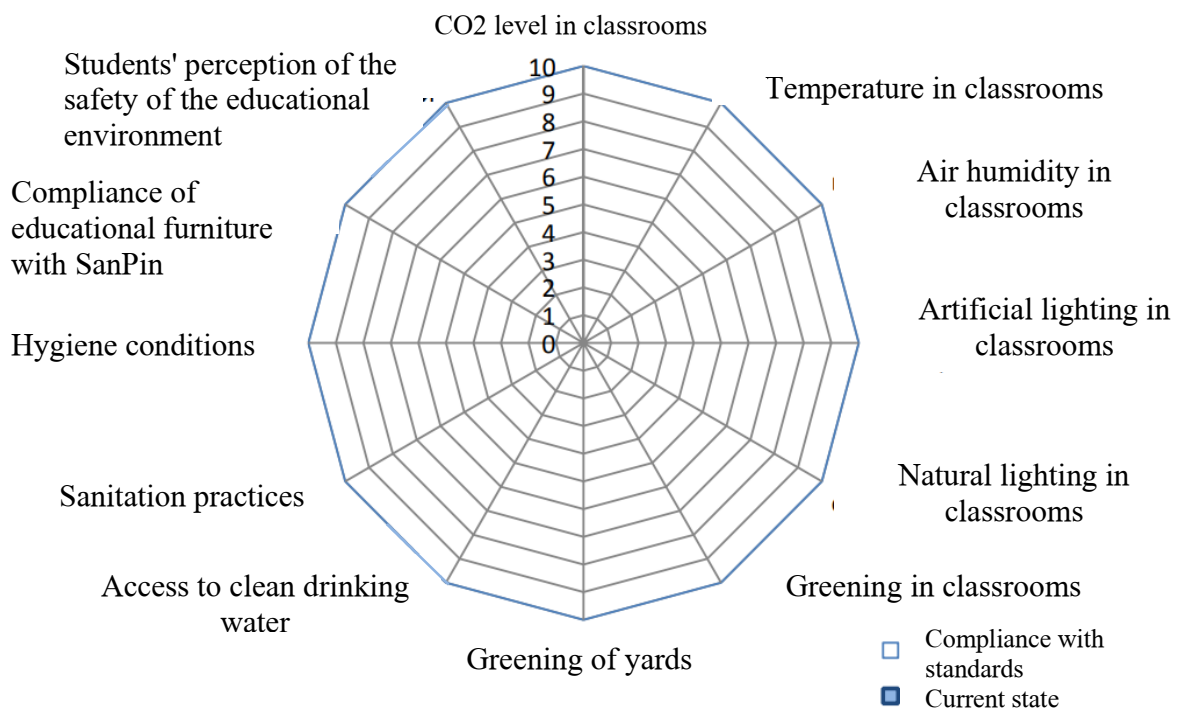

Fig. 1. A safety radar

The monitoring made it possible to provide the education management system (Ministry of Education and Science of the Kyrgyz Republic) with modern and reliable information that allows assessing the indicators of the state of the environmental security of the school, as well as to develop recommendations for assistance in the security of the physical school environment to make informed management decisions, and to increase the awareness of consumers of educational services. 


\section{Results and Discussion}

An educational environment is an environment that supports the development of a person into an independent and active student, carries the core values of the curriculum and the spirituality of its school, and preserves and develops local intellectual traditions of the school. In a broad sense, the learning environment can be conditionally divided into several aspects, which jointly form a safe environment is formed. A safe school environment includes several aspects:

- Physical security (safe buildings including in emergencies, training equipment, etc.),

- Environmental (environment-forming) security (clean air, water, sanitation, healthy food, high-quality lighting, the correct ratio of temperature, ventilation, energy efficiency, landscaping, etc.).,

- Safe psychological environment (non-discriminatory, tolerant environment, nonviolent, non-conflict behavior).

Based on the conducted research, several important changes in regulatory and legal documents were developed and consolidated by the Resolution of the Government of the Kyrgyz Republic. They were aimed at eliminating contradictions in the legislation of the Kyrgyz Republic, making amendments, as well as harmonizing previously adopted decisions of the Government of the Kyrgyz Republic to improve the safety of the educational environment in educational institutions. In particular, conflicts between Sanitary Rules and Regulations and building codes and rules were eliminated.

Based on the results of the study, based on the monitoring of the safety of the educational environment and the consequent changes in schools, a Comprehensive Safety Standard for schools of the Kyrgyz Republic was developed and approved by the Decree of the Government of the Kyrgyz Republic. The purpose of this regulatory document was to ensure a safe educational process and protect the health of students by supplementing the requirements for organizing a safe educational environment in educational institutions of the Kyrgyz Republic. The document stipulates the requirements for the organization of a safe educational environment in general educational institutions of the Kyrgyz Republic and specifies the mechanisms for its provision. The comprehensive safety standard was developed with the support of the project "Development of mechanisms for financing the safety of the school educational environment in the Kyrgyz Republic", which is implemented by the K. Adenauer and Ecological Movement "BIOM" in partnership with the Ministry of Education and Science of the Kyrgyz Republic, with the financial support of the European Union.

The development of the standard took place with active public involvement. The main norms of the standard were tested in pilot schools in cooperation with school principals, parents, and local authorities. In particular, pilot schools tested the mechanisms of safe procurement, energy efficiency, and greening of their territory.

The standard regulates several basic elements of a safe environment: physical, biological, psychological, and informational. The standard helps assess the state of schools by these parameters, as well as improve the educational environment so that it meets the established standards. The document completely changes the approach to the formation of the educational space in the schools of the republic subject to the safety requirements.

In a broad sense, the learning (educational) environment as a system can be conditionally divided into several sub-spheres, which jointly form a safe environment. In international practice, models of two types of the safety of the educational environment necessary and sufficient security - were previously identified. The model of "necessary safety" can be presented in the following provisions: 1) physical protection; 2) psychological protection; and 3) environmental (sanitary and hygienic) protection. The 
model of "sufficient security" includes additionally: 4) social; 5) economic; 6) informational; 7) educational types of protection.

Following the recommendations obtained from the results of the study, the following components were included in the standard for a safe educational environment:

- psychological/social security (non-discriminatory, non-violent and tolerant environment);

- physical security (safe buildings including in emergencies, training equipment, etc.),

- environmental safety (clean air, water, sewerage, healthy food, high-quality lighting, correct temperature, ventilation, energy efficiency, gardening, etc.).

As a result of the project "Development of mechanisms for financing the safety of the school educational environment in the Kyrgyz Republic", 11 pilot schools changed their educational space.

\section{Conclusion}

The emerging global world has become increasingly filled with new global threats and dangers, causing global crises, exacerbating global problems, and even leading to intercountry disasters. The multiplication of challenges, threats, and dangers in the course of global processes turns security in all its forms and kinds into one of the main universal human goals, values, and problems of the XXI century related to ensuring the preservation and further development of civilization. Thus, a need arises for a systemic, holistic, and proactive approach, a consideration of global security not only as the security of the entire world community but at the same time the "man-society" and "man-society-nature" systems.

The results of the study turned out to be consistent with and confirming the relationships previously identified in world practice:

- the quality of the educational environment influences the motivation of students to study, their health and well-being;

- the relationship between improving the school environment and reducing violence, the level of improving school safety was identified;

- the direct relationship between the "friendliness" of space and freedom of movement, research, and study was confirmed;

- a positive relationship was established between the "personalization" of the space and the involvement of children in its design and their self-esteem, motivation, and behavior, especially for primary school children.

The normal harmonious development and functioning of the human psyche need a visually diverse, creative environment that contributes to the support of an individual educational trajectory, aesthetics, the implementation and development of the creative potential of children.

The above results show that the application of integrated safety practices in various components accompanying the educational process can become a basic scenario for the development of new educational programs for sustainable development. Thus, during the transition to sustainable development, security ceases to be only one of the conditions for development but becomes its necessary component. Meanwhile, development turns out to be an integral component of ensuring security, which is expressed in the form of the "security through sustainable development" principle. This principle acts as the main ambitious conceptual idea of the national security of Russia or any other country that has joined the process of transition to sustainable development, and, in the foreseeable future, of the entire world community. 


\section{Acknowledgments}

The research was carried out within the framework of the project "Development of mechanisms for financing the safety of the school educational environment in the Kyrgyz Republic", implemented by the K. Adenauer Fund and the Ecological Movement "BIOM" in partnership with the Ministry of Education and Science of the Kyrgyz Republic with the financial support of the European Union.

\section{References}

1. Action Programme on Education for Sustainable Development (2015-2019), https://en.unesco.org/

2. Tetiana H. Malolitneva, European Journal of Sustainable Development, 9 (2), 42 (2020)

3. V. OrlovicLovren, M. Maruna, S. Stanarevic, International Journal of Sustainability in Higher Education, 21(2), 315 (2020)

4. ESD for 2030: What's next for Education for Sustainable Development?, https://en.unesco.org/

5. K. Shulla, W.L. Filho, S. Lardjane, J.H. Sommer, C. Borgemeister, International Journal of Sustainable Development and World Ecology, 27 (5), 458 (2020)

6. E.G. García, E.C. Magaña, A.C. Ariza, Sustainability,12 (15) (2020)

7. N. Giangrande, R.M. White, M. East, R. Jackson, T. Clarke, M.S. Coste, G.A. PenhaLopes, Sustainability, 11 (10) (2019)

8. H. Glasser, J. Hirsh, Sustainability, 9 (3),121 (2016)

9. Y. Mochizuki, Z. Fadeeva, International Journal of Sustainability in Higher Education, 11 (4), 391 (2010)

10. Georgetown University Press, 334 (2012)

11. Mark Duffield, Global Governance and the New Wars: The Merging of Development and Security, 56 (2014)

12. Council of the European Union, General Secretariat of the Council, Council Conclusions on Operationalizing the Humanitarian-Development Nexus (2017), http://www.consilium.europa.eu/

13. Dewi, E.K., Himam, F., Sobirin, A. Developing Security Climate in Educational Organizations in the Cyber Era (2020) IOP Conference Series: Earth and Environmental Science, 448 (1)

14. S.Kapelari, G.Alexopoulos, T.Moussouri, K.J.Sagmeister, F.Sustainability, 12 (4)

15. D.Fróna, J.Szenderák, M.Harangi-Rákos, Sustainability, 11 (20) (2019)

16. P.Soares, M.A.Martínez-Mián, P.Caballero, C.Vives-Cases, M.C.Davó-Blanes, Gaceta Sanitaria, 31 (6), 466 (2017)

17. M.Oostindjer, J.Aschemann-Witzel, Q.Wang, S.E.Skuland, B.Egelandsdal, G.V.Amdam, Schjøll A., M.C.Pachucki, P.Rozin, J.Stein, V.LengardAlmli, E.Van Kleef, Crit Rev Food Sci Nutr., 57(18), 3942 (2017)

18. P.Soares, M.C.Davó-Blanes, Gaceta Sanitaria, 33 (3), 213 (2019)

19. Y.Kitamura, IATSS Research, 38 (1), 40 (2014)

20. De l'évidence à l'ambiguïté, 242 (2012) 